\title{
Phase I/II intra-patient dose escalation study of vorinostat in children with relapsed solid tumor, lymphoma, or leukemia
}

Cornelis M. van Tilburg ${ }^{1,2,3+}$ (D) Till Milde ${ }^{1,2,3+}$, Ruth Witt ${ }^{1,3}$, Jonas Ecker ${ }^{1,2,3}$, Thomas Hielscher ${ }^{4}$, Angelika Seitz ${ }^{5}$, Jens-Peter Schenk ${ }^{6}$, Juliane L. Buhl ${ }^{1,3,7}$, Dennis Riehl ${ }^{8}$, Michael C. Frühwald ${ }^{9}$, Arnulf Pekrun ${ }^{10}$, Claudia Rossig ${ }^{11}$, Regina Wieland ${ }^{12}$, Christian Flotho ${ }^{13}$, Uwe Kordes ${ }^{14}$, Bernd Gruhn ${ }^{15}$, Thorsten Simon ${ }^{16}$, Christin Linderkamp ${ }^{17}$, Felix Sahm ${ }^{18,19}$, Lenka Taylor ${ }^{20}$, Angelika Freitag ${ }^{21}$, Jürgen Burhenne ${ }^{22}$, Kathrin I. Foerster ${ }^{22}$, Andreas D. Meid ${ }^{22}$, Stefan M. Pfister ${ }^{1,2,23}$, Irini Karapanagiotou-Schenkel ${ }^{21+}$ and Olaf Witt ${ }^{1,2,3^{*}+}$

\begin{abstract}
Background: Until today, adult and pediatric clinical trials investigating single-agent or combinatorial HDAC inhibitors including vorinostat in solid tumors have largely failed to demonstrate efficacy. These results may in part be explained by data from preclinical models showing significant activity only at higher concentrations compared to those achieved with current dosing regimens. In the current pediatric trial, we applied an intra-patient dose escalation design.

The purpose of this trial was to determine a safe dose recommendation (SDR) of single-agent vorinostat for intrapatient dose escalation, pharmacokinetic analyses (PK), and activity evaluation in children (3-18 years) with relapsed or therapy-refractory malignancies.

Results: A phase I intra-patient dose (de)escalation was performed until individual maximum tolerated dose (MTD). The starting dose was $180 \mathrm{mg} / \mathrm{m}^{2} /$ day with weekly dose escalations of $50 \mathrm{mg} / \mathrm{m}^{2}$ until DLT/maximum dose. After MTD determination, patients seamlessly continued in phase II with disease assessments every 3 months. PK and plasma cytokine profiles were determined. Fifty of 52 patients received treatment. $n=27 / 50(54 \%)$ completed the intra-patient (de)escalation and entered phase II. An SDR of $130 \mathrm{mg} / \mathrm{m}^{2} /$ day was determined (maximum, $580 \mathrm{mg} / \mathrm{m}^{2} /$ day). $n=46$ / 50 (92\%) patients experienced treatment-related AEs which were mostly reversible and included thrombocytopenia, fatigue, nausea, diarrhea, anemia, and vomiting. $n=6 / 50$ (12\%) had treatment-related SAEs. No treatment-related deaths occurred. Higher dose levels resulted in higher $C_{\max }$. Five patients achieved prolonged disease control (> 12 months) and showed a higher $C_{\max }(>270 \mathrm{ng} / \mathrm{mL}$ ) and MTDs. Best overall response (combining PR and SD, no CR observed) rate in phase II was 6/27 (22\%) with a median PFS and OS of 5.3 and 22.4 months. Low levels of baseline cytokine expression were significantly correlated with favorable outcome.

(Continued on next page)
\end{abstract}

\footnotetext{
* Correspondence: o.witt@kitz-heidelberg.de

${ }^{+}$Cornelis M. van Tilburg and Till Milde contributed equally to this work.

† Irini Karapanagiotou-Schenkel and Olaf Witt are co-senior authors.

${ }^{1}$ KiTZ Clinical Trial Unit, Hopp Children's Cancer Center Heidelberg (KiTZ),

German Cancer Research Center (DKFZ) and Heidelberg University Hospital,

Im Neuenheimer Feld 430, 69120 Heidelberg, Germany

${ }^{2}$ Department of Pediatric Oncology, Hematology and Immunology,

Heidelberg University Hospital, Heidelberg, Germany

Full list of author information is available at the end of the article
}

(c) The Author(s). 2019 Open Access This article is distributed under the terms of the Creative Commons Attribution 4.0 International License (http://creativecommons.org/licenses/by/4.0/), which permits unrestricted use, distribution, and

reproduction in any medium, provided you give appropriate credit to the original author(s) and the source, provide a link to the Creative Commons license, and indicate if changes were made. The Creative Commons Public Domain Dedication waiver (http://creativecommons.org/publicdomain/zero/1.0/) applies to the data made available in this article, unless otherwise stated. 


\begin{abstract}
(Continued from previous page)
Conclusion: An SDR of $130 \mathrm{mg} / \mathrm{m}^{2} /$ day for individual dose escalation was determined. Higher drug exposure was associated with responses and long-term disease stabilization with manageable toxicity. Patients with low expression of plasma cytokine levels at baseline were able to tolerate higher doses of vorinostat and benefited from treatment. Baseline cytokine profile is a promising potential predictive biomarker.
\end{abstract}

Trial registration: ClinicalTrials.gov, NCT01422499. Registered 24 August 2011,

Keywords: Vorinostat, Intra-patient dose escalation, Dose-response, Cytokine, Child, HDAC

\section{Background}

Children and adolescents with relapsed or therapyrefractory malignancies have low chances of cure [13], implying an unmet clinical need for new therapies [4]. Histone deacetylase inhibitors (HDACi) such as vorinostat, panobinostat, belinostat, romidepsin, and entinostat have shown promising anti-tumor activity in preclinical models and adult clinical trials particularly in leukemia [5]. Vorinostat was the first HDACi to be FDA-approved for the treatment of adult patients with cutaneous $\mathrm{T}$-cell lymphoma with persistent or recurrent disease on or following systemic cytotoxic therapies [6]. Vorinostat is an oral pan-HDACi targeting a broad range of HDACs including HDAC1, HDAC2, and HDAC3 (Class I) and HDAC6 (Class IIb) [7]. Inhibition of HDACs by HDACi induces hyperacetylation of histones and many other cytoplasmic proteins leading to cell cycle arrest, apoptosis, autophagy, and/or cell death.

Several early phase clinical trials using vorinostat as single agent or in combination for various pediatric oncology indications have been performed [8-12]. A pediatric recommended phase 2 dose of $230 \mathrm{mg} / \mathrm{m}^{2} /$ day was identified for daily and continuous dosing, which approximates the adult dose (adjusted for body surface area) [10]. Substantial variability in pharmacokinetic (PK) parameters was noted, but in general, median AUC and $\mathrm{C}_{\max }$ appeared to be higher than in adults [13]. In addition, several other combinatorial and noncontinuous regimens have been reported (daily dose ranging $180-430 \mathrm{mg} / \mathrm{m}^{2} /$ day) $[8,9,11,12,14]$. Unfortunately, pediatric clinical trials up until now failed to show efficacy $[8-12,14]$ although individual patients with selected indications clearly benefited from vorinostat treatment [15]. The disappointing clinical results in solid tumors may in part be explained by preclinical data in which vorinostat showed significant antitumoral activity only at higher concentrations compared to those achieved with currently applied dosing regimens [16], including neuroblastoma [17] and brain tumor [18] models. At the same time, adult clinical studies suggest that treatment response correlates with dose and a subgroup of patients tolerate doses exceeding the approved dose by up to four-fold [19, $20]$. In the current trial, we, therefore, applied an intrapatient dose escalation design in order to maximize the likelihood of response whilst keeping toxicity acceptable for the individual patient.

We report the results of a single-arm phase I/II trial of single-agent vorinostat in children and adolescents with relapsed/refractory solid tumor, lymphoma, or leukemia. The primary objective was to define a safe dose recommendation (SDR) involving a subsequent individual dose escalation regimen. Secondary objectives included PK and to determine tumor response rates, safety, and feasibility. Accompanying exploratory plasma cytokine analyses aimed for predictive biomarker discovery.

\section{Results \\ Patients}

Of the 58 patients screened, 52 were enrolled (three patients did not fulfill inclusion criteria, one had an exclusion criterion, parents refused for one, and one patient died during screening). Two patients were enrolled but did not receive any study medication and were excluded from analysis (in one patient, an exclusion criterion occurred and one had an SAE after which informed consent was withdrawn), resulting in 50 evaluable patients (Fig. 1) (safety population). Patients were enrolled from May 11, 2012, to September 28,2016 . Twenty-eight (56\%) patients were male and $22(44 \%)$ female. The age for the total population was $10.9 \pm 4.1$ years (mean $\pm \mathrm{SD}$ ). The most common diagnoses were brain tumors, followed by sarcomas and several other entities (Table 1).

Of the 50 patients, 27 (54\%) completed the intrapatient (de)escalation period and had at least one visit in the phase II part of the trial receiving vorinostat at their individual MTD (efficacy population). There were no significant demographic and baseline characteristic differences between the safety and efficacy population at baseline (Table 1). There were no neuroblastoma or leukemia patients present in the efficacy population: hence, all tumors were evaluated using RECIST version 1.1. 


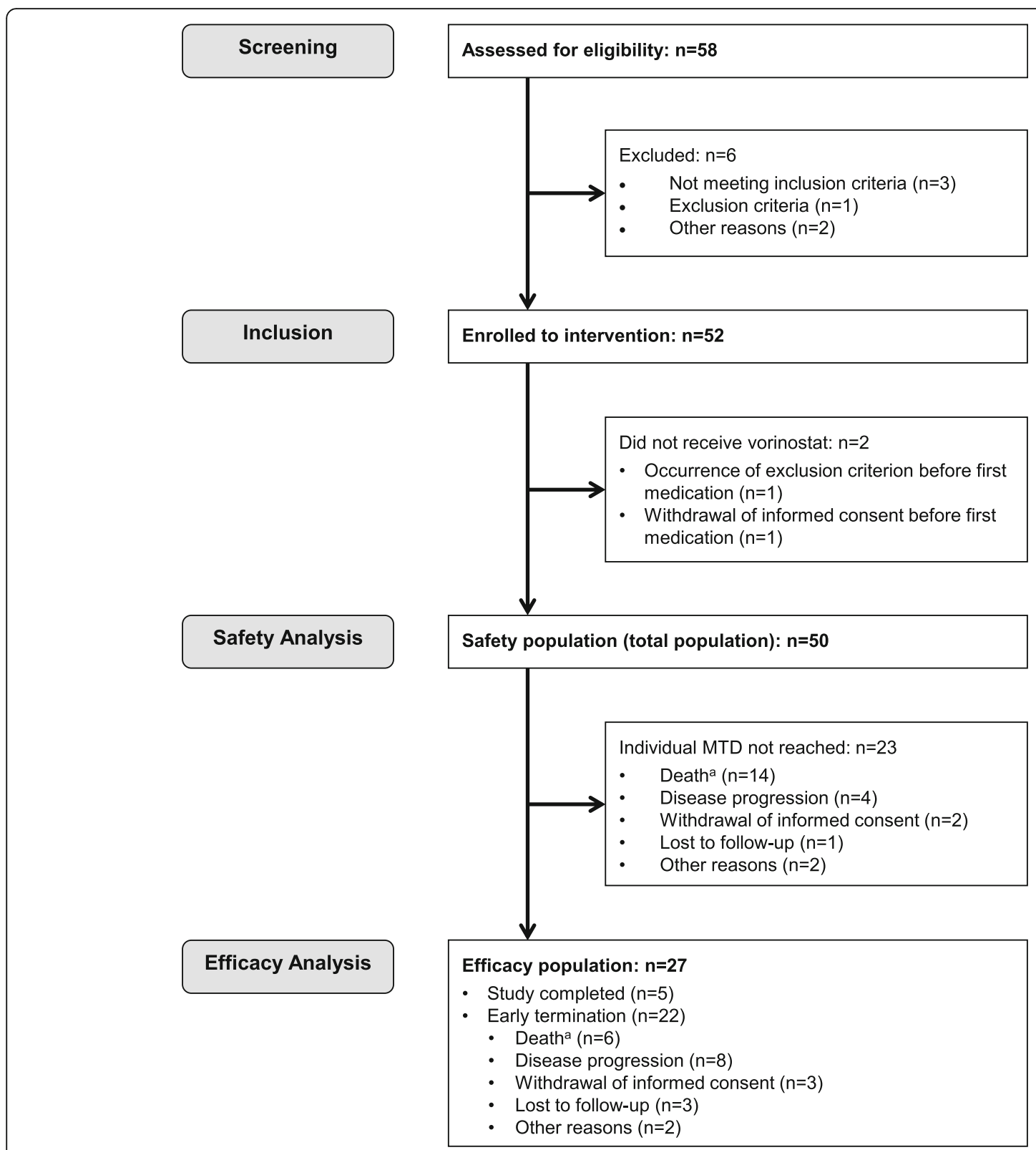

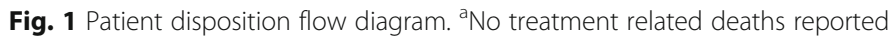

\section{Safety}

The safety population comprised all 50 patients. The median duration of drug exposure was 102 days (range, 1-485 days). Ten different dose levels were administered ranging from $130 \mathrm{mg} / \mathrm{m}^{2} /$ day to $580 \mathrm{mg} / \mathrm{m}^{2} /$ day, most of the patients received three $(n=14 / 50,28 \%)$ or four ( $n=9 / 50,18 \%)$ different dose levels. Out of 50,48 (96\%) of patients had a starting dose of $180 \mathrm{mg} / \mathrm{m}^{2} /$ day and $4 /$ $50(8 \%)$ of patients reached the maximum individual MTD of $580 \mathrm{mg} / \mathrm{m}^{2} /$ day (median individual MTD, $280 \mathrm{mg} / \mathrm{m}^{2} /$ day) (Additional file 4). An SDR (defined as the highest dose with a DLT in no more than $1 / 50$ patients) as starting dose for subsequent individual dose escalation was $130 \mathrm{mg} / \mathrm{m}^{2} /$ day. During the study, four patients needed de-escalation to $130 \mathrm{mg} / \mathrm{m}^{2} /$ day and one of them had DLTs at this dose. There were up to 9 DLTs per patient, but most patients had one $(n=12 / 50$, $24 \%)$ or two ( $n=10 / 50,20 \%)$ DLTs. Most DLTs were related to the blood and lymphatic system, most commonly decreased platelet counts (52 DLTs) followed by decreased white blood cell count (11 DLTs). Most frequent non-hematological DLTs were fatigue (7 DLTs), hyponatremia, and nausea (both four DLTs). Other DLTs mostly concerned gastrointestinal disorders and metabolism and nutrition disorders (e.g., electrolyte disturbances) (Table 2). 
Table 1 Baseline characteristics for eligible patients

\begin{tabular}{|c|c|c|}
\hline \multirow[t]{2}{*}{ Characteristic } & Safety population $(n=50)$ & Efficacy population $(n=27)$ \\
\hline & No $(\%)$ & No $(\%)$ \\
\hline \multicolumn{3}{|l|}{ Sex } \\
\hline Female & $28(56)$ & $12(44)$ \\
\hline Male & $22(44)$ & $15(56)$ \\
\hline Age, years, median (range) & $11(3-18)$ & $11(5-17)$ \\
\hline \multicolumn{3}{|l|}{ Diagnosis } \\
\hline \multicolumn{3}{|l|}{ Brain tumors } \\
\hline High-grade glioma & $19(38)$ & $11(41)$ \\
\hline Medulloblastoma & $8(16)$ & $4(15)$ \\
\hline Ependymoma & $3(6)$ & $2(7)$ \\
\hline Low grade glioma & $2(4)$ & 0 \\
\hline PNET & $1(2)$ & $1(4)$ \\
\hline Other $^{a}$ & $1(2)$ & $1(4)$ \\
\hline \multicolumn{3}{|l|}{ Extracranial solid tumors } \\
\hline Ewing sarcoma & $4(8)$ & $3(11)$ \\
\hline Osteosarcoma & $4(8)$ & $2(7)$ \\
\hline Neuroblastoma & $2(4)$ & 0 \\
\hline DSRCT & $2(4)$ & $1(4)$ \\
\hline Soft tissue sarcoma & $1(2)$ & $1(4)$ \\
\hline Wilms tumor & $1(2)$ & 0 \\
\hline SETTLE tumor & $1(2)$ & $1(4)$ \\
\hline \multicolumn{3}{|l|}{ Leukemia } \\
\hline AML & $1(2)$ & 0 \\
\hline \multicolumn{3}{|l|}{ Lansky score } \\
\hline 100 & $9(18)$ & $5(19)$ \\
\hline 90 & $13(27)$ & $8(30)$ \\
\hline 80 & $14(29)$ & $11(41)$ \\
\hline 70 & $6(12)$ & $2(7)$ \\
\hline 60 & $7(14)$ & $1(4)$ \\
\hline Missing & $1(2)$ & 0 \\
\hline
\end{tabular}

Baseline characteristics for eligible patients for both the total population (safety population) at baseline $(n=50)$ and the efficacy population (population which reached their individual MTD: $(n=27))$, separately

$D S R C T$, desmoplastic small round cell tumor; SETTLE, spindle epithelial tumor with thymus like differentiation

${ }^{a}$ Malignant pleomorphic neuroepithelial tumor

AEs were considered as treatment related if the relationship was reported as "related," "probable," "possible," or missing. The majority of the patients $(n=46 / 50,92 \%)$ experienced treatment-related AEs, $n=6 / 50(12 \%)$ of them had treatment-related SAEs. A total of $n=42 / 50$ (84\%) patients experienced severe treatment-related AEs (CTCAE grade 3 or 4 ) of which most were reversible. $n=6 / 50(12 \%)$ patients discontinued treatment and $n=$ $35 / 50(70 \%)$ patients had dose reductions or temporary discontinuations due to treatment-related AEs (Additional file 5). No treatment-related deaths were reported. The most common treatment-related AE was decreased platelet count $(n=37 / 50$ patients, $74 \%)$ of which $n=15$ were grade 3 and 16 grade 4 . Other frequent treatment-related AEs (mostly grade CTCAE grades $1-2$ ) were fatigue in $n=16 / 50(32 \%)$, nausea in $n=15 / 50(30 \%)$, diarrhea in $n=12 / 50$ (24\%), anemia in $n=10 / 50(20 \%)$, and vomiting in $n=10 / 50(20 \%)$ patients (Table 3).

\section{Efficacy}

The efficacy population consisted of $n=27 / 50$ (54\%) patients who completed the intra-patient (de)escalation period and had at least one visit in the phase II part of the trial at their individual MTD. $n=5 / 27$ (18.5\%) patients reached the end of the maximum treatment period 
Table 2 Patients with DLT per dose level (safety population, $n=50$ ).

\begin{tabular}{|c|c|c|c|c|c|c|c|c|c|c|c|}
\hline \multirow[t]{2}{*}{ DLT } & \multicolumn{10}{|c|}{ Patients (\%) with DLT per dose level (mg/m²/day) } & \multirow{2}{*}{$\begin{array}{l}\text { Total } \\
\text { sum } \\
\text { of } \\
\text { DLTs }\end{array}$} \\
\hline & 130 & 180 & 230 & 280 & 330 & 380 & 430 & 480 & 530 & 580 & \\
\hline \multicolumn{12}{|l|}{ Hematological DLTs } \\
\hline Platelet count decreased & & $6(12 \%)$ & $8(16 \%)$ & $13(26 \%)$ & $6(12 \%)$ & $4(8 \%)$ & $4(8 \%)$ & $3(6 \%)$ & $4(8 \%)$ & $3(6 \%)$ & $52^{a}$ \\
\hline White blood cell decreased & & $1(2 \%)$ & $3(6 \%)$ & $2(4 \%)$ & $2(4 \%)$ & $1(2 \%)$ & $1(2 \%)$ & & & $1(2 \%)$ & 11 \\
\hline Anemia & & $1(2 \%)$ & & & & & & & & $1(2 \%)$ & 2 \\
\hline \multicolumn{12}{|l|}{ Non-hematological DLTs } \\
\hline Fatigue & $1(2 \%)$ & $1(2 \%)$ & $1(2 \%)$ & $1(2 \%)$ & & & $1(2 \%)$ & $1(2 \%)$ & & $1(2 \%)$ & 7 \\
\hline Hyponatremia & & $2(4 \%)$ & & & $1(2 \%)$ & & $1(2 \%)$ & & & & 4 \\
\hline Nausea & $1(2 \%)$ & $1(2 \%)$ & $1(2 \%)$ & $1(2 \%)$ & & & & & & & 4 \\
\hline Alanine aminotransferase increased & & $1(2 \%)$ & $2(4 \%)$ & & & & & & & & 3 \\
\hline Decreased appetite & $1(2 \%)$ & $1(2 \%)$ & $1(2 \%)$ & & & & & & & & 3 \\
\hline Hypermagnesemia & & & & $1(2 \%)$ & $1(2 \%)$ & & $1(2 \%)$ & & & & 3 \\
\hline Abdominal pain upper & $1(2 \%)$ & $1(2 \%)$ & & & & & & & & & 2 \\
\hline Febrile infection & & & & $1(2 \%)$ & & & & & & $1(2 \%)$ & 2 \\
\hline Vomiting & & & $1(2 \%)$ & $1(2 \%)$ & & & & & & & 2 \\
\hline Weight decreased & & & $1(2 \%)$ & & & & & & & $1(2 \%)$ & 2 \\
\hline Abdominal pain & & & & $1(2 \%)$ & & & & & & & 1 \\
\hline Aggression & & $1(2 \%)$ & & & & & & & & & 1 \\
\hline Apathy & & $1(2 \%)$ & & & & & & & & & 1 \\
\hline Hypokalemia & & & $1(2 \%)$ & & & & & & & & 1 \\
\hline Loss of personal independence in daily activities & & & & & & & $1(2 \%)$ & & & & 1 \\
\hline
\end{tabular}

Patients can have several DLTs at the same time at the same dose level. Furthermore, due to the intra-patient dose (de-)escalation design, patients could be treated in several dose levels, resulting in more DLTs at respective dose levels

${ }^{a}$ Including 1 accidental overdose $\left(714 \mathrm{mg} / \mathrm{m}^{2} /\right.$ day), data not depicted

of 12 months. The other $n=22 / 27$ patients $(81.5 \%)$ terminated the study prematurely. Reasons for premature termination were death in $n=6(27 \%)$, disease progression in $n=8(41 \%)$, withdrawal of informed consent in $n=3$ (14\%), lost to follow-up in $n=3$ (9\%), and other reasons in $n=2(9 \%)$ cases. The median duration of drug exposure in the efficacy population was 164 days (range, 29-485 days).

At first response evaluation (after 3-month treatment at individual MTD), $n=3 / 27$ patients showed partial response (PR, 11\%) and $n=2 / 27$ showed stable disease (SD, 7\%). After 6 months of treatment at individual MTD, an additional PR occurred, resulting in a best overall response rate (combining PR and SD, no CR observed) of $22 \%$ (Table 4). The median duration of response was 19.1 months. Median progression-free survival (PFS) and overall survival (OS) were 5.3 and 22.4 months, respectively, for the efficacy population (Table 4 and Fig. 2a, b)

Of the five patients who reached the end of study (stayed on treatment $>12$ months), all had an individual MTD in the highest dose levels and four patients had PR as best response (Table 5). Some of these patients continued treatment for several years beyond the study observation period (not in included in data analysis). Among these were two patients with continued partial response and clinical benefit who received prolonged treatments. One patient with a centrally confirmed histological diagnosis of glioblastoma WHO IV (DNA methylation profile: pilocytic astrocytoma with BRAFV600E mutation) received vorinostat for a total duration of 3.5 years and continued to be in partial remission 1 year after treatment cessation. One patient with a pulmonary metastasized spindle epithelial tumor with thymus-like differentiation (SETTLE) received vorinostat for a total duration of 5 years with continued partial response. Progression occurred after discontinuation of vorinostat.

\section{Pharmacokinetic studies}

PK evaluation was performed on day 8 after start treatment, at the time of reaching the individual MTD and 3 months thereafter (at the time of the first response evaluation). $\mathrm{A} \mathrm{C}_{\max }$ for all ages and dose levels normalized to $1 \mathrm{mg}$ of vorinostat per day $\left(\mathrm{C}_{\max } / \mathrm{D}\right)$ of $1.70 \pm 1.18((\mathrm{ng} /$ $\mathrm{mL}) /(\mathrm{mg} / \mathrm{d}))$, a $\mathrm{T}_{\max }$ of $2.07 \pm 1.37 \mathrm{~h}$ and $\mathrm{T}_{1 / 2}$ of $1.98 \pm$ 
Table 3 Treatment related AEs

\begin{tabular}{|c|c|c|c|c|}
\hline \multirow[b]{2}{*}{ Adverse event } & \multicolumn{4}{|c|}{ Patients (\%, 95\% Cls) with AE (maximum Grade CTCAE v4.0) } \\
\hline & Grade 1 - 2 & Grade 3 & Grade 4 & Total of patients with $\mathrm{AE}$ \\
\hline \multicolumn{5}{|l|}{ Hematological AEs } \\
\hline Platelet count decreased & $6(12.0)$ & $15(30.0)$ & $16(32.0)$ & $37(74.0,59.7-85.4)$ \\
\hline Anemia & $8(16.0)$ & $2(4.0)$ & & $10(20.0,10.0-33.7)$ \\
\hline White blood cell decreased & $1(2.0)$ & $8(16.0)$ & & $9(18.0,8.6-31.4)$ \\
\hline \multicolumn{5}{|l|}{ Non-hematological AEs } \\
\hline Fatigue & $9(18.0)$ & $7(14.0)$ & & $16(32.0,19.5-46.7)$ \\
\hline Nausea & $11(22.0)$ & $4(8.0)$ & & $15(30.0,17.9-44.6)$ \\
\hline Diarrhea & $11(22.0)$ & $1(2.0)$ & & $12(24.0,13.1-38.2)$ \\
\hline Vomiting & $8(16.0)$ & $2(4.0)$ & & $10(20.0,10.0-33.7)$ \\
\hline Alopecia & $9(18.0)$ & & & $9(18.0,8.6-31.4)$ \\
\hline Weight decreased & $5(10.0)$ & $3(6.0)$ & & $8(16.0,7.2-29.1)$ \\
\hline Decreased appetite & $5(10.0)$ & $2(4.0)$ & & $7(14.0,5.8-26.7)$ \\
\hline Headache & $5(10.0)$ & $1(2.0)$ & & $6(12.0,4.5-24.3)$ \\
\hline Blood creatinine increased & $5(10.0)$ & & & $5(10.0,3.3-21.8)$ \\
\hline Alanine aminotransferase increased & $2(4.0)$ & $2(4.0)$ & & $4(8.0,2.2-19.2)$ \\
\hline Blood lactate dehydrogenase increased & $4(8.0)$ & & & $4(8.0,2.2-19.2)$ \\
\hline Constipation & $4(8.0)$ & & & $4(8.0,2.2-19.2)$ \\
\hline Dry skin & $4(8.0)$ & & & $4(8.0,1.3-16.5)$ \\
\hline Cough & $3(6.0)$ & & & $3(6.0,1.3-16.5)$ \\
\hline Hypermagnesemia & & $3(6.0)$ & & $3(6.0,1.3-16.5)$ \\
\hline Pyrexia & $3(6.0)$ & & & $3(6.0,1.3-16.5)$ \\
\hline
\end{tabular}

Incidence and maximum severity (the maximum grade for every AE per patient is depicted for the duration of the study) of treatment related AEs occurring in at least $5 \%$ of patients according to CTCAE v4.0 (safety population, $n=50$ ). "Treatment related" was defined as a relationship reported as "related", "probable" or missing. No treatment related deaths were reported

$0.96 \mathrm{~h}$ were detected. Table 6 summarizes further PK results for all ages and dose levels. PK data according to dose level is provided in the Additional files 1 and 6. Although there was substantial interpatient variability, $C_{\max }$ was higher in the higher dose levels (Additional file 1), whereas for area under the curve (AUC), this was not the case (data not shown). An explorative analysis showed that patients who achieved a higher $C_{\max }$ (and thus received higher doses) had longer PFS (Fig. 2c). The five patients who achieved prolonged disease control (>12 months) all had a $\mathrm{C}_{\max }$ of $>270 \mathrm{ng} / \mathrm{mL}$ with highrange individual MTDs from 280-580 $\mathrm{mg} / \mathrm{m}^{2} /$ day (response, survival, and dosing can be found in Table 5). The tumors of the five patients who achieved prolonged disease control all had different histology (Table 5). Of note, brain tumors were enriched in this group. No relevant influence of age on PK parameters was detected. Explorative analyses did not reveal correlation between most frequently occurring toxicity, i.e., thrombocytopenia, and dose/ PK parameters like $\mathrm{T}_{\max }$ or AUC (data not shown).

Table 4 Efficacy end points

\begin{tabular}{lll}
\hline End point & Safety population $(n=50)$ & Efficacy population $(n=27)$ \\
\hline Best RR $(\mathrm{CR}+\mathrm{PR}), \mathrm{No} .(\%, 95 \% \mathrm{Cl})$ & $4(8.0,2.2-19.2)$ & $4(14.8,4.2-33.7)$ \\
Best ORR (CR + PR + SD), No. (\%, 95\% Cl) & $6(12.0,4.5-24.3)$ & $6(22.2,8.6-42.3)$ \\
Median response duration, months & 19.1 & 19.1 \\
Median PFS, months (95\% Cl) & $4.6(3.7-5.3)$ & $5.3(4.6-5.9)$ \\
Median OS, months (95\% Cl) & $6.1(4.0-10.4)$ & $22.4(6.3---)$ \\
\hline
\end{tabular}

$R R$, response rate; $C R$, complete response (not observed); $P R$, partial response; $S D$, stable disease; $O R R$, overall response rate; $P F S$, progression free survival; $O S$, overall survival 


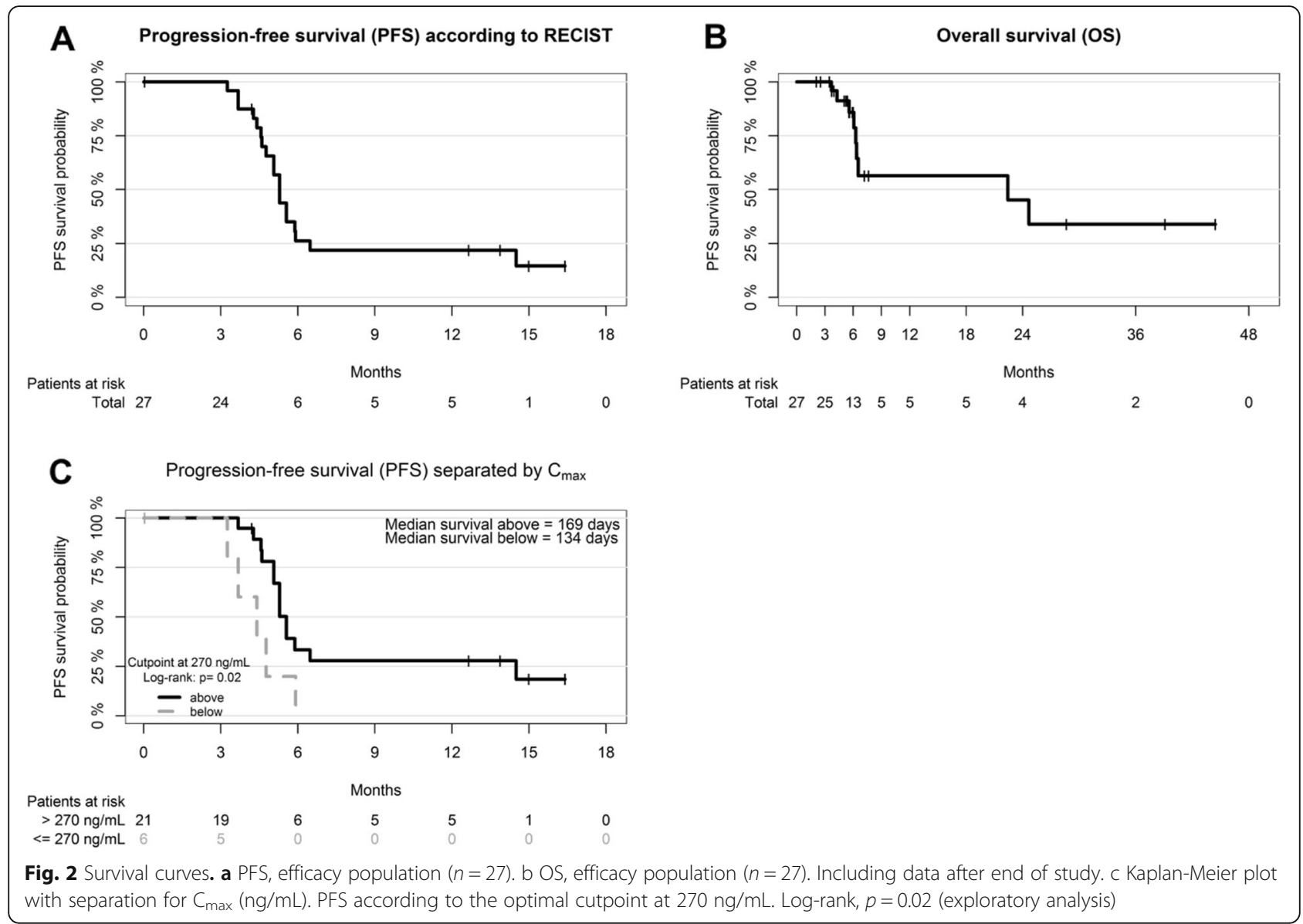

Table 5 Diagnosis, response, survival, dosing and molecular data of long term survivors

\begin{tabular}{|c|c|c|c|c|c|c|c|c|c|}
\hline \multirow[t]{2}{*}{$\begin{array}{l}\text { Histological } \\
\text { diagnosis }\end{array}$} & \multirow[t]{2}{*}{$\begin{array}{l}\text { Best } \\
\text { response }\end{array}$} & \multirow{2}{*}{$\begin{array}{l}\text { PFS } \\
\text { Days }\end{array}$} & \multirow{2}{*}{$\begin{array}{l}\text { OS } \\
\text { Days }\end{array}$} & \multirow[t]{2}{*}{$\begin{array}{l}\text { Last } \\
\text { known } \\
\text { status }\end{array}$} & \multirow{2}{*}{$\begin{array}{l}\text { MTD } \\
\mathrm{mg} / \\
\mathrm{m}^{2} / \\
\mathrm{d}\end{array}$} & \multirow{2}{*}{$\begin{array}{l}\text { Last } \\
\text { dose } \\
\text { level } \\
\mathrm{mg} / \\
\mathrm{m}^{2} / \mathrm{d}\end{array}$} & \multirow[t]{2}{*}{$\begin{array}{l}\text { Methylation } \\
\text { profile }\end{array}$} & \multirow[t]{2}{*}{ Copy number variations } & \multirow[t]{2}{*}{ Mutations and variants } \\
\hline & & & & & & & & & \\
\hline $\begin{array}{l}\text { High grade } \\
\text { glioma }\end{array}$ & PR & $\begin{array}{l}385 \\
(C)\end{array}$ & $\begin{array}{l}1352 \\
\text { (C) }\end{array}$ & Alive & 280 & 280 & $\begin{array}{l}\text { Pilocytic } \\
\text { astrocytoma }\end{array}$ & - & BRAF (p.V600E) \\
\hline Medulloblastoma & SD & $\begin{array}{l}422 \\
\text { (C) }\end{array}$ & $\begin{array}{l}871 \\
(C)\end{array}$ & Alive & 580 & 430 & $\begin{array}{l}\text { Not attributable; } \\
\text { highest score for } \\
\text { medulloblastoma } \\
\text { group } 4\end{array}$ & - & - \\
\hline $\begin{array}{l}\text { High grade } \\
\text { glioma }\end{array}$ & PR & $\begin{array}{l}441 \\
(\mathrm{NC})\end{array}$ & $\begin{array}{l}750 \\
(\mathrm{NC})\end{array}$ & Deceased & 530 & 530 & $\begin{array}{l}\text { Not attributable; } \\
\text { highest score for } \\
\text { glioblastoma IDH } \\
\text { wt }\end{array}$ & $\begin{array}{l}\text { Homozygous loss of } \\
\text { CDKN2A/B; several gains, } \\
\text { e.g. } 7 p(\text { EGFR), 9q (PTCH), } \\
11 \text { ( (CCND1); several } \\
\text { losses, e.g.: 10q (MGMT) }\end{array}$ & $\begin{array}{l}\text { Mutations: TP53 (p.R174X), ATRX } \\
\text { (p.R907X), NF1 (p.R1968X); } \\
\text { variants (no germline data } \\
\text { available): RET (p.R820H), BCRA2 } \\
\text { (p.E2856A), ATR (p.Y1462C), } \\
\text { PIK3C2G (p.N1211S), TP53 } \\
\text { (p.G113S) }\end{array}$ \\
\hline SETTLE tumor & PR & $\begin{array}{l}456 \\
(C)\end{array}$ & $\begin{array}{l}1190 \\
\text { (C) }\end{array}$ & Alive & 580 & 580 & - & No aberrations & Mutations: none; variants: none \\
\hline $\begin{array}{l}\text { High grade } \\
\text { glioma }\end{array}$ & PR & $\begin{array}{l}499 \\
\text { (C) }\end{array}$ & $\begin{array}{l}682 \\
(\mathrm{NC})\end{array}$ & Deceased & 530 & 280 & - & - & - \\
\hline
\end{tabular}

Overview of patients with partial reponse and/or long term stable disease (reaching > 12 months treatment). Abbreviations: PFS progression free survival, OS overall survival, MTD maximal tolerable dose, (C) censored, (NC) not censored, SETTLE spindle epithelial tumor with thymus like differentiation 
Table 6 Pharmacokinetic parameters

\begin{tabular}{|c|c|c|c|c|c|c|}
\hline & $\begin{array}{l}C_{\max } / \mathrm{D} \\
((\mathrm{ng} / \mathrm{mL}) /(\mathrm{mg} / \mathrm{d}))\end{array}$ & $\begin{array}{l}T_{\max } \\
\text { (h) }\end{array}$ & $\begin{array}{l}\mathrm{AUCO}_{0 \text {-inf }} / \mathrm{D} \\
((\mathrm{ng} / \mathrm{mL} * \mathrm{~h}) /(\mathrm{mg} / \mathrm{d}))\end{array}$ & $\begin{array}{l}t_{1 / 2} \\
\text { (h) }\end{array}$ & $\begin{array}{l}\text { Clearance } \\
(\mathrm{L} / \mathrm{h})\end{array}$ & $\begin{array}{l}V_{z} \\
(L)\end{array}$ \\
\hline No. of Samples & 86 & 86 & 66 & 79 & 79 & 79 \\
\hline Mean & $1.70 \pm 1.18$ & $2.07 \pm 1.37$ & $5.49 \pm 2.75$ & $1.98 \pm 0.96$ & $235 \pm 149$ & $644 \pm 460$ \\
\hline
\end{tabular}

PK parameters ( \pm SD). Means of all ages and dose levels

$C_{\max } / D$, maximum concentration normalized to $1 \mathrm{mg}$ vorinostat per day; $T_{\max }$ time at maximum concentration; $A U C 0_{\text {inf }} / D$, area under the curve from 0 to infinitive normalized to $1 \mathrm{mg}$ vorinostat per day; $\mathrm{t}_{1 / 2}$, half-life time of vorinostat; $\mathrm{V}_{\mathrm{z},}$ distribution volume

\section{Biomarker analyses}

HDAC inhibitors have been shown to modulate expression of immune-related genes and regulate cytokine production in several preclinical models [21]. Therefore, cytokine profiles in plasma samples of study subjects from which at least two blood samples including the baseline sample were available were determined. A total number of $n=119$ plasma samples from $n=43$ patients from a maximum of $n=4$ time points (baseline, $n=43$ samples; day $8, n=40$ samples; MTD day $1, n=21$ samples; and at 3 months after reaching MTD; $n=15$ samples) were measured by multiplex assay covering 27 cytokines.

A high correlation between individual cytokines at baseline was detected (Additional file 2), suggesting a high intra-patient correlation of the measured cytokines. Unsupervised clustering of the cytokine profiles at baseline revealed two separate clusters (1 and 2), with cluster "high" characterized by high and cluster "low" by low cytokine levels (Fig. 3a). Both clusters differed statistically significantly for PFS and OS $(p<$ 0.0005 and $p<0.005$ respectively) (Fig. $3 \mathrm{~b}$ ), with "low" cytokine levels associated with a favorable PFS and OS. Within cluster "low," two sub-clusters ("low" and "intermediate") were distinguishable, with statistically different PFS and OS overall (Fig. 3c), again with "low" cytokine levels associated with a favorable PFS and OS. The measurement of 9 cytokines was sufficient to distinguish the three clusters "high," "intermediate," and "low" (Additional file 2). On a single factor level, measurement of, e.g., IL8 alone was able to discriminate between the groups "high" and "low" (cluster 1) (Additional file 3), and IL9 and MIP1b in addition discriminated between the groups "high," "intermediate," and "low" (cluster 2) (Additional file 3).

Longitudinal analysis of samples revealed no significant differences in mean concentration over time, as detected at the four time points analyzed, separated either by MTD groups $\left(\geq 280 \mathrm{mg} / \mathrm{m}^{2},<280 \mathrm{mg} / \mathrm{m}^{2}\right.$, or MTD not reached; Additional file 2) or by best response groups (PR/SD, PD, not assessable; Additional file 2) indicating stable cytokine profiles in individual patients. In summary, exploratory biomarker analysis revealed low baseline plasma cytokine levels as indicator of favorable clinical outcome.

\section{Discussion}

Our pediatric phase I/II study of vorinostat in children and adolescents with relapsed/refractory malignancies identified a safe starting dose of $130 \mathrm{mg} / \mathrm{m}^{2} /$ day for individual dose escalation with weekly increments of $50 \mathrm{mg} /$ $\mathrm{m}^{2}$. Although the median individual MTD reached after individual dose escalation was $280 \mathrm{mg} / \mathrm{m}^{2} /$ day, 4/50 of patients reached the maximum individual MTD of $580 \mathrm{mg} / \mathrm{m}^{2} /$ day, confirming that higher doses can be tolerated by individual patients, as has been published in earlier adult trials and also observed in a recent study in neuroblastoma [14]. Most common treatment-related $\mathrm{AE}$ was decreased platelet count followed by fatigue, nausea, diarrhea, anemia, and vomiting. This AE profile is similar to what has been reported for vorinostat in other pediatric and also adult studies. No treatmentrelated deaths were reported.

An important limitation of the study design is that the definition of SDR was potentially too rigid. The definition did not account for whether DLTs resolved without severe sequelae after discontinuation (in other words, were manageable), as was the case for the most frequent DLTs, i.e., blood and lymphatic system DLTs. This resulted in a SDR of $130 \mathrm{mg} / \mathrm{m}^{2} /$ day for individual dose escalation (dose level 1), which may seem contradictory to the median individual MTD of $280 \mathrm{mg} / \mathrm{m}^{2} /$ day. It seems feasible to start vorinostat treatment at one or two dose levels higher (180 or $230 \mathrm{mg} / \mathrm{m}^{2} /$ day) without significantly compromising safety as long as patients are closely monitored (blood counts, electrolytes, GI disturbances) and weekly increments of $50 \mathrm{mg} / \mathrm{m}^{2}$ are not exceeded.

Exploratory analysis demonstrated that dose escalation to doses higher than the currently recommended pediatric dose [10] of $230 \mathrm{mg} / \mathrm{m}^{2} /$ day, corresponding to the approved adult dose of $400 \mathrm{mg} /$ day, resulted in higher $C_{\max }$ and was associated with tumor response and longer progression free survival. The five patients who achieved prolonged disease control all had a $\mathrm{C}_{\max }$ of $>270 \mathrm{ng} / \mathrm{mL}$ which corresponds to preclinical testing data from pediatric cancer models which showed significant activity only at median IC50 of $1.44 \mu \mathrm{M}$ (381 ng/ $\mathrm{mL}$ ) [16]. Furthermore, since the HDAC inhibitory activity of vorinostat closely follows the drug concentration due to a short lifetime of the drug-target complex as has 
A

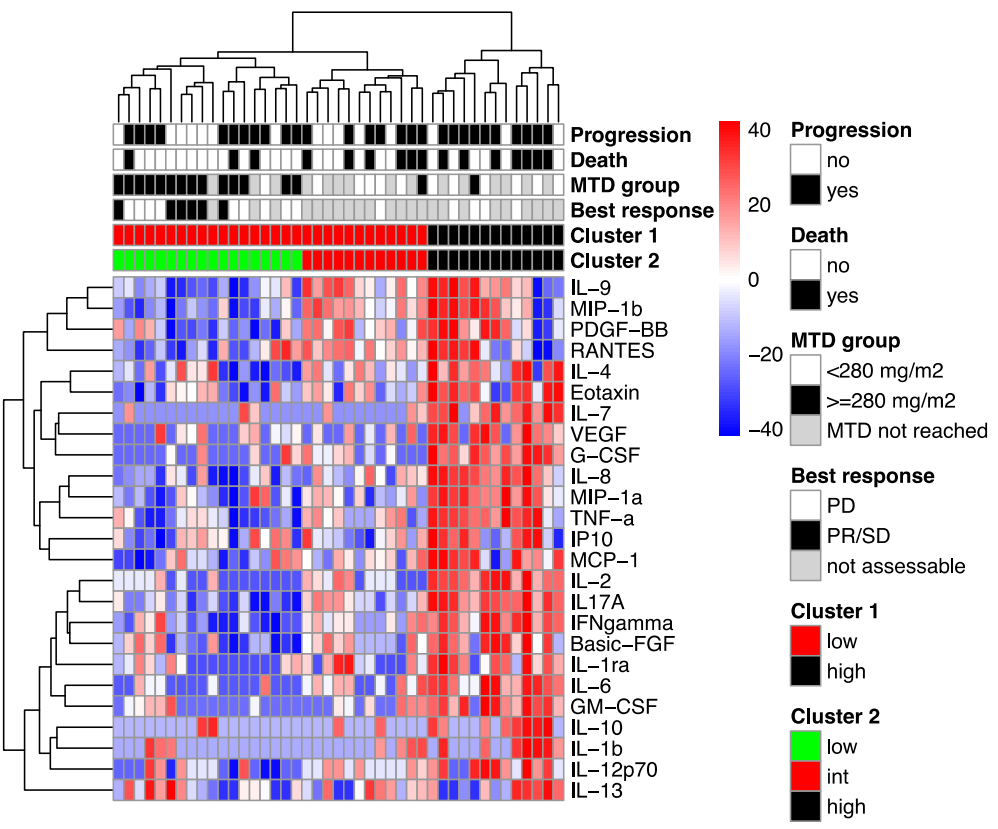

B
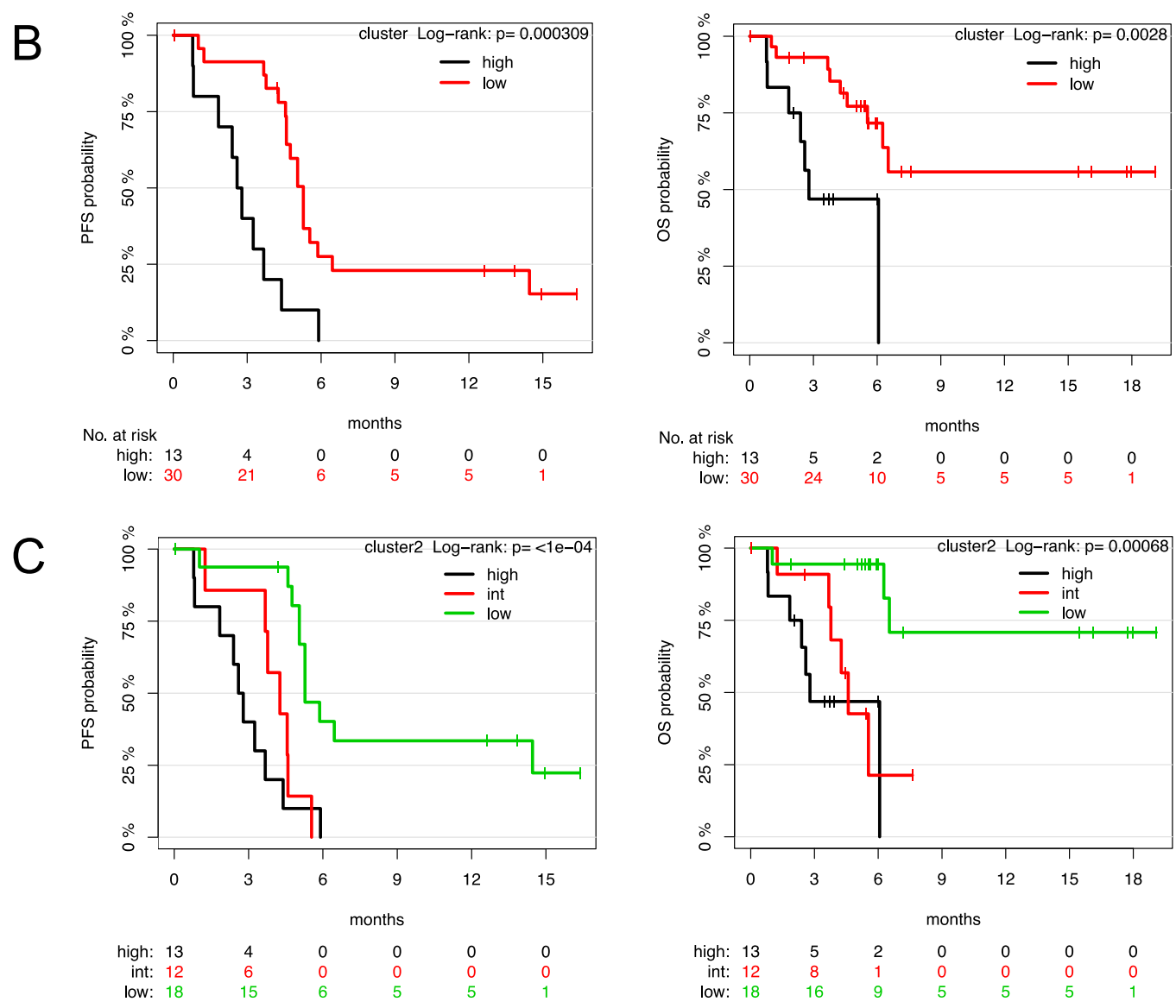

int vs high : $p=0.278-$ low vs high $: p=<0.001-$ low vs int $: p=<0.001$

int vs high : $p=0.410-$ low vs high $: p=<0.001-$ low vs int $: p=0.003$

Fig. 3 (See legend on next page.) 
(See figure on previous page.)

Fig. 3 Low levels of cytokine expression at baseline define a cohort with favorable outcome. a Heat map of baseline concentrations (Gehan uscore). MTD group, $<280=$ MTD reached was below $280 \mathrm{mg} / \mathrm{m}^{2},>=280=$ MTD reached was equal to or above $280 \mathrm{mg} / \mathrm{m}^{2}$, not reached = MTD was not reached; Best Response: PD: best response progressive disease; PR/SD: best response partial response or stable disease; not assessable: best response not assessable. $\mathbf{b}$ PFS and OS Kaplan-Meier plot according to cytokine cluster high and low. c PFS and OS Kaplan-Meier plot according to cytokine cluster high, intermediate (int), and low in cluster 2

been shown in preclinical models [18], it is well conceivable that a higher $\mathrm{C}_{\max }$ leads to longer inhibition of HDAC. This observation underlines the importance of intra-patient dose escalation of vorinostat as single agent in order to maximize the likelihood of benefit for the patient.

The vorinostat PK data are in the range of previously published pediatric vorinostat PK [10-12]. Investigators in these studies did, however, not increase to doses above $300 \mathrm{mg} / \mathrm{m}^{2}$, but also used the doses of 180,230 , and $300 \mathrm{mg} / \mathrm{m}^{2}$ and published steady-state AUCs between 817 and $2963 \mathrm{ng} / \mathrm{mL}^{*} \mathrm{~h}$, which is in line with the range of 752 to $2574 \mathrm{ng} / \mathrm{mL}^{*}$ h determined in this study (130-330 $\mathrm{mg} / \mathrm{m}^{2}$ dosing). With higher dosing (up to $580 \mathrm{mg} / \mathrm{m}^{2}$ ) AUCs up to $3840 \mathrm{ng} / \mathrm{mL}$ \% $\mathrm{h}$ were reached. Further PK data $\left(\mathrm{T}_{1 / 2}, \mathrm{~T}_{\max }, \mathrm{Cl} / \mathrm{F}, \mathrm{V}_{\mathrm{D}}\right)$ was also comparable [11]. Inter-individual variability of vorinostat in patients is high, which is well known for vorinostat [2224] due to absorbance variability with different meals or fasted. In comparison to adult data, children exposures calculated as AUC were reported to be substantial higher $[19,23,25]$ and could be confirmed by the data in this study. The adults show longer half-lives and the clearance is higher than in children suggesting that tissue distribution in adults is more pronounced [19].

The overall response rate of $22 \%$ (combining PR and $\mathrm{SD}$, no CR observed) was lower as reported by trials in comparable populations (46\%), whereas the observed OS (median 22.4 months) was longer as reported in comparable populations (9.0 months) [1]. Among the four patients experiencing a partial response, three had a national reference neuropathology diagnosis of high-grade glioma (HGG) suggesting that this may be a target population for future studies as suggested by others [26] and suggesting blood-brain barrier penetrance in agreement with preclinical observations by others [27-29]. Molecular analyses of archived tumor material from primary diagnosis revealed that one of those patients with HGG displayed the molecular features of BRAFV600E-mutated pilocytic astrocytoma. The observation of a responding molecularly defined BRAF-mutated pilocytic astrocytoma is intriguing in light of the recently discovered ability of vorinostat to induce apoptosis by increasing reactive oxygen species (ROS) levels in BRAFV600E-mutated melanomas [30]. A total of two patients with continued PR and clinical benefit tolerated treatment with vorinostat for up to 5 years, indicating long-term tolerability.
Predictive biomarkers for the treatment with HDACis are scarce. Immunohistochemistry for HR23B has been shown to be a positive predictive marker for response to vorinostat [31] and for belinostat [32] in clinical studies. Preclinical studies indicate $M Y C$ amplification as a potential predictive marker for HDACi treatment $[18,33]$. Since several HDAC inhibitors have shown immunemodulatory effects in preclinical models $[21,34]$ and more recently, to act synergistically with immune checkpoint inhibitors [35-38] we sought to correlate plasma cytokine profiles with clinical outcome in our study. Surprisingly, unsupervised clustering revealed a cohort of patients with favorable outcome defined by low levels of cytokine expression at baseline. Furthermore, all five patients exhibiting partial responses/prolonged stable disease with a favorable clinical outcome showed a low cytokine expression profile at baseline. In contrast, adult phase I/II trials of vorinostat in clear-cell renal cell carcinoma [39] and panobinostat in lymphoma [40, 41] did not detect a difference of baseline cytokine expression profiles between responders and non-responders. Of note, our trial did not enroll patients with any of these tumors and the determined cytokine profiles differed compared to these adult studies. Thus, our data suggests that baseline plasma cytokine levels can potentially serve as predictive biomarker for treatment response and/or improved tolerability to $\mathrm{HDACi}$ such as vorinostat in pediatric cancers requiring further prospective investigation. It remains poorly understood by which biological mechanism each single cytokine interacts with vorinostat and the immune system, and how this relates to antitumoral activity of vorinostat, which should be addressed in future studies.

\section{Conclusion}

Intra-patient dose escalation of vorinostat in children and adolescents with relapsed/refractory malignancies seems feasible, results in manageable toxicity, and can induce partial responses or disease stabilization in a fraction of patients. Higher dose levels of vorinostat correlate with plasma peak levels expected to have antitumoral activity in pediatric preclinical cancer models and were associated with a more favorable clinical outcome in the present study. This warrants further studies including prospective evaluation of baseline cytokine profile as a predictive biomarker for HDACi tolerability 
and/or response in certain subpopulations like HGG. The first pediatric studies are in preparation and will validate the potential predictive role of the baseline cytokine profile (NCT03838042).

\section{Methods \\ Eligibility criteria}

Children and adolescents (3-18 years) with relapsed or therapy-refractory solid tumors (including brain tumors), lymphoma, or leukemia following standard first-line or relapse protocols in pediatric oncology were eligible. Reference-confirmed diagnosis by one of the pathological, radiological, or study reference centers recognized by the Society for Pediatric Oncology und Hematology (GPOH) in Germany was required. No other simultaneous anti-neoplastic treatment or radiotherapy during the study and 2 weeks before enrolment was allowed. Other eligibility criteria included adequate general condition (Lansky Score $>50 \%$ ) and life expectancy $>3$ months, liver enzymes (ALT or AST) $<\times 5$ upper limit of normal reference value, bilirubin and creatinine $<\times 3$ upper limit of normal reference value, solid tumors: leukocytes $>2000 / \mu \mathrm{l}$, thrombocytes $>50.000 / \mu \mathrm{l}$ and adequate bone marrow function to permit evaluations of hematopoietic toxicity, no CTCAE grade 3 or 4 toxicity from previous treatments (no persistent CTCAE $\geq$ grade 3 toxicity from previous treatments), normal ECG. For solid tumors (including brain tumors), measurable disease activity according to Response Evaluation Criteria in Solid Tumors (RECIST) version 1.1 was required. Written informed consent of the legal representatives and the patient (if the patient was able to understand the study situation and to give consent) was mandatory. Women with childbearing potential had to agree to use adequate contraception or to abstain from heterosexual activity throughout the study, starting with Visit 1 , and sexually active male patients had to agree to use an adequate method of contraception for the duration of the study. Patients were excluded if they had a history of deep vein thrombosis or pulmonary embolism, were pregnant or lactating, and used concomitant treatments and/or anti-neoplastic treatment such as chemotherapy, immune therapy, and differentiation therapy, other targeted therapy, or received radiotherapy. The use of valproic acid as prior antiepileptic therapy was allowed with a 14-day washout period. Other exclusion criteria included prior exposure to $\mathrm{HDACi}$, known active $\mathrm{HBV}, \mathrm{HCV}$, or HIV infection, the use of concomitant treatments such as amber (Hypericum perforatum), plant extracts, vitamins, and other anti-oxidative compounds, participation in other clinical trials or observation period of competing trials, respectively, unable to swallow vorinostat suspension or capsules, and use of coumarin- derivative anticoagulants and any other medication which could accentuate known dose-dependent adverse effects of the study drug, for instance bone marrow depression or QT-prolongation.

\section{Study design and treatment}

The study design was a single-arm, multi-center phase I/ II clinical trial with two phases: Phase I was an intrapatient dose (de)escalation period until an individual maximum tolerable dose (MTD) was reached. The vorinostat dose was escalated with increments of $50 \mathrm{mg} / \mathrm{m}^{2} /$ day every week until dose limiting toxicity (DLT) occurred or a maximum dose of $580 \mathrm{mg} / \mathrm{m}^{2} /$ day was reached (Additional file 4). The maximum dose was chosen based on early phase I adult dose escalation experience demonstrating that this was the highest tolerable dose, maximum drug exposure/on target activity, and clinical responses seen in individual cases [20]. A DLT was defined as grade 3 or 4 toxicity according to a selection of Common Toxicity Criteria for Adverse Events (CTCAE) (V4.0) and judged by the investigator as definitely, probably, or possibly related to the study drug. The starting dose was $180 \mathrm{mg} / \mathrm{m}^{2} /$ day and the minimum dose was $30 \mathrm{mg} / \mathrm{m}^{2} /$ day. A dosing nomogram was used to minimize interpatient dosing variability.

In case of a DLT, vorinostat was discontinued until toxicity had declined to grade 2 or less and treatment could then be resumed at the previous dose without grade 3 or 4 toxicity (reduction by $50 \mathrm{mg} / \mathrm{m}^{2} /$ day). This dose was defined as the individual MTD. If a DLT already occurred at the starting dose, vorinostat was discontinued until toxicity had declined to at least grade 2 or less and treatment was continued with $130 \mathrm{mg} / \mathrm{m}^{2} /$ day (Additional file 1). De-escalation was done in steps of $50 \mathrm{mg} / \mathrm{m}^{2} /$ day until a minimal dose of $30 \mathrm{mg} / \mathrm{m}^{2} /$ day was reached. If de-escalation resulted in a dose $<30 \mathrm{mg} /$ $\mathrm{m}^{2} /$ day, treatment was discontinued. Upon reaching her or his individual MTD, a patient seamlessly entered phase II of the protocol.

In phase II, during which vorinostat was administered at the individual MTD, the same de-escalation rules were applied. During phase II, disease assessments were performed every 3 months, starting 3 months after reaching individual MTD. If treatment was discontinued for any reason during phase II, treatment was prolonged thereafter to provide a minimal treatment window of 3 months before measuring response. Patients without progressive disease continued the therapy at their individual MTD until disease progression (but no longer than 9 months). In case of clinical benefit, treatment could be continued on an individual basis at the discretion of the investigator. Toxicities were graded according CTCAE V4.0. 
Vorinostat was provided as 100-mg capsules (hard gelatin capsules) or suspension $50 \mathrm{mg} / \mathrm{ml}$ (capsules dispersed in OraPlus/OraSweet), both for once daily oral administrations with food. Capsules were supplied by Merck, Sharp \& Dome (MSD) Germany, and drug distribution and suspension preparation were performed by the Heidelberg University Hospital Pharmacy Department.

\section{Study end points and assessments}

The primary end point was to determine a safe dose recommendation (SDR), defined as the highest dose with a DLT in no more than $1 / 50$ patients. Secondary end points included PK analyses at the first dose level and at the individual MTD, best overall response rate (combining $\mathrm{CR}, \mathrm{PR}$, and SD) after 3 months treatment at individual MTD and every 3 months thereafter, determination of duration of response and assessment of feasibility and safety of the intra-patient dose escalation design and treatment at MTD in the phase II part of the trial thereafter. Cytokine profiles as potential biomarker for response prediction to vorinostat were determined in an exploratory manner.

Pretreatment evaluations included medical history, physical examination, ECG, ß-hCG in urine pregnancy test (if applicable), and complete blood count including differential, serum electrolytes liver, and renal function tests. Tumor markers were determined if appropriate. During phase I and the first 3 months of phase II (until the first response evaluation), history, physical examination, and laboratory studies were obtained weekly. If patients continued treatment beyond the first response evaluation in phase II (i.e., not showing PD), evaluations were performed every 2 weeks. After end of treatment, patients were followed-up for 3 months according the same scheme. In addition, an ECG was performed during phase I on day 8,15 , and at the time of reaching the individual MTD. Disease evaluations were performed at baseline, after 3 months of treatment at individual MTD, and every 3 months thereafter, using MRI (solid tumors, brain tumors, lymphomas), MIBG scan (neuroblastoma), or bone marrow evaluation (leukemia). Responses were reported using RECIST version 1.1 (solid tumors, brain tumors, lymphomas) [42-44] or the International Neuroblastoma Response Criteria (INRC) (neuroblastoma) [45], by central review. Bone marrow aspirates were evaluated in a central lab together with peripheral blood differential blood counts.

\section{Pharmacokinetic studies}

PK evaluation was performed at day 8 after start treatment, at the time of reaching the individual MTD, and 3 months thereafter (at the time of the first response evaluation). Samples (2-mL citrate-blood) were collected before, $0.5,1,1.5,2,4,6$, and $8 \mathrm{~h}$ after oral vorinostat administration. Vorinostat plasma concentrations were quantified according to previously published methods [46].

The assays were validated according to the common FDA and EMA guidelines on bioanalytical method validation. Lower limit of quantification of vorinostat was $11.0 \mathrm{ng} / \mathrm{mL}$. The calibrated vorinostat range was 11.0 $1100 \mathrm{ng} / \mathrm{mL}$ with correlation coefficients $>0.99$. The overall accuracy varied between $-6.7 \%$ and $+3.8 \%$ and the overall precision ranged from 3.2 to $6.1 \%$.

\section{Biological analyses}

Biomarker evaluation (cytokine profiles) was performed at baseline, day 8 , at the time of reaching the individual MTD, and 3 months thereafter (3 mL citrate blood). Cytokine measurements in plasma samples were performed using multiplex assay ("Luminex") as described [47]. $n=27$ different cytokines/chemokines were analyzed in one sample using Bio-Plex ProTM Human Cytokine 27-plex Assay (cat. no. 244 M500KCAF0Y, Bio-Rad) according to the manufacturer's protocol. Molecular profiling was done by DNA methylation array [48] and custom gene panel sequencing [49] in patients with long-term disease stabilization if archival tumor material was available.

\section{Statistical analyses \\ Safety and efficacy}

The justification for the sample size was based on accuracy requirements for the SDR. Fifty pediatric patients were to be included in the trial. If DLT was observed at a given dose $d$ in no more than $1 / 50$ patients (this defines the SDR for routine application), then the upper bound of the 95\% confidence interval for the true rate $r$ of DLT at this dose was $\leq 10.65 \%$. The DLT associated with the starting dose was to be continuously monitored using a Bayesian criterion with a non-informative prior and a binomial-beta model for the DLT rate $r$. If, for the second and following patients, the posterior probability that $r>10 \%$ was $95 \%$ or higher, the starting dose used for the following patients had to be lowered by $50 \mathrm{mg} /$ $\mathrm{m}^{2}$. This decision process was repeated, i.e., it was applied to the lowered starting dose in an analogous way. If, during dose escalation, a patient experienced drugrelated life-threatening symptoms or death, dose escalation for the following patients had to be stopped one dose step below this toxic dose.

Apart from the estimation of the SDR and the treatment response rates with exact two-sided 95\% CI according to Clopper-Pearson [50], the statistical analysis was explorative and mainly descriptive. Standard methods for survival analysis (e.g., Kaplan-Meier estimates of the survival curves, Greenwood's formula for 
estimating the standard error of event rates) were used for the analysis of time-to-event endpoints. The main analysis based on the safety analysis set included all enrolled patients who had taken at least one dose of trial treatment. Efficacy analysis included all patients who had completed the escalation/de-escalation scheme and started with the individual therapy at the MTD.

All adverse events were summarized, using MedDRA preferred terms. Serious adverse event presentations were derived from a separate, centralized, adverse event monitoring database that was continuously updated based on rapidly communicated reports from the investigators to the sponsor.

\section{Pharmacokinetic analyses}

PK parameters were calculated by non-compartmental analysis using plasma concentrations of vorinostat $\left(C_{\max } / D\right.$, $\mathrm{T}_{\mathrm{Max}}, \mathrm{AUC} / \mathrm{D}, \mathrm{T}_{1 / 2}$, clearance $\mathrm{Cl} / \mathrm{F}$, and distribution Volume $\left.V_{z} / F\right)$. The AUCs were calculated by mixed log-linear model. Following exploratory aims to predict progression free survival (PFS) and overall survival (OS), an optimal cutpoint in the continuous PK parameter distributions of $C_{\max }$ and $\mathrm{AUC} / \mathrm{D}$ was determined by the minimum $p$ value approach based on the log-rank test [51]. Graphical and statistical analysis was performed with Graphpad Prism 7.0 (Graphpad Software Inc., La Jolla, CA, USA), Kinetica 5.0 (Thermo Fisher Scientific, Waltham, MA, USA), and the R software/environment version 3.5.1 (R Foundation for Statistical Computing, Vienna, Austria).

\section{Biomarker evaluation (cytokine profiles)}

Values below the lowest standard curve value were extrapolated. Values below the assay detection limit (out of range, OOR), i.e., below extrapolated values, were treated as left-censored. IL5 and IL15 were almost only OOR and therefore not informative, and excluded from further analysis. Hierarchical clustering of samples based on baseline concentrations was performed after Gehan's U-score transformation of ranked cytokine levels was applied. L1-penalized logistic regression was used to discard strongly correlated cytokines for cluster assignment. Log-rank test was used to compare prognosis between clusters. Spearman's correlation coefficient was used to assess pairwise correlation between cytokines. Mean values were estimated using Regression on Order Statistics with the R package NADA [52].

\section{Supplementary information}

Supplementary information accompanies this paper at https://doi.org/10. 1186/s13148-019-0775-1.

Additional file 1: Figure S1. a Linear correlation $C_{\max }(n g / m L)$ - Dose $\left(\mathrm{mg} / \mathrm{m}^{2} / \mathrm{d}\right)$. $\mathbf{b}$ Concentration of vorinostat in plasma according to dose level.
Additional file 2: Figure S2. a Plot of pairwise correlations (Spearman) of baseline concentrations of individual cytokines. $\mathbf{b}$ Heatmap of baseline concentrations (Gehan u-score) of a selection of 9 cytokines. c Longitudinal analysis of mean values of cytokines, separated by MTD groups. $\mathbf{d}$ Longitudinal analysis of mean values of cytokines, separated by best response groups.

Additional file 3: Figure S3. Cluster discrimination on single factor levels. a Receiver operating characteristic curve (ROC) for IL8 discriminating "high" and "low" (cluster 1), showing high correlation of sensitivity and specificity resulting in good predictivity. b Boxplot of IL8 cytokine concentrations in groups "high" and "low" (cluster 1). c and d: boxplots of cytokines IL9 (c) and MIP1b (d) showing additional discrimination of clusters "high", "intermediate" and "low" (cluster 2).

Additional file 4: Table S1. Dose levels and DLTS.

Additional file 5: Table S2. Summary of safety data.

Additional file 6: PK parameters ( \pm SD). Medians and means of all dose levels.

\section{Acknowledgements}

The trial was supported by a grant from the German Childhood Cancer Foundation, Bonn, Germany (DKS 2009.16). Study drug was provided by MSD Sharp \& Dohme. The authors thank all families and children participating in this study as well as all participating GPOH pediatric oncology centers in Augsburg, Bremen, Cologne, Essen, Freiburg, Hamburg, Hannover, Jena, and Muenster. The authors also acknowledge Marlene Diewald for data management and Donate Jakoby and Sabine Brokmeier for operational support.

We thank the NCT3.0 program of the National Center for Tumor Diseases (NCT) providing infrastructural support (ZIPO) as well as the "Verein für krebskranke Kinder Odenwald" and "Aktion für krebskranke Kinder Heidelberg" for supporting preclinical and translational work on HDAC biology in pediatric cancers.

\section{Authors' contributions}

RW, LT, IK, and OW carried out the conception and design of the study. CMVT, TM, MCF, AP, CR, RW, CF, UK, BG, TS, CL, SMP, and OW carried out the provision of patients. AF participated in the collection and assembly of data. AS and JS performed the central radiology review. CMvT, TM, RW, JE, TH, JLB, $\mathrm{DR}, \mathrm{FS}, \mathrm{AF}, \mathrm{JB}, \mathrm{KIF}, \mathrm{ADM}$, IK, and OW carried out the data analysis and interpretation. CMvT, TM, and OW carried out the paper writing. All authors contributed to discussions about the design of the study, enrolled the patients, and read and approved the manuscript.

\section{Funding}

This study was funded by the German Childhood Cancer Foundation, Bonn, Germany (Grant number: DKS 2009.16). Drug support was provided by MSD Sharp \& Dohme.

\section{Availability of data and materials}

Datasets supporting the conclusions of this article are included within the article and its additional files. In addition, the datasets used and/or analyzed during the current study are available from the corresponding author on reasonable request.

\section{Ethics approval and consent to participate}

The final protocol, amendments, and informed consent and any other appropriate documents were reviewed and approved by the Independent Ethics Committee(s) (IEC) at each of the investigational centers (reference number Heidelberg University Hospital: AFmu-286/2008) participating in the study and the German competent authority (BfArM). The study was conducted in accordance with the principles of the Declaration of Helsinki and the Good Clinical Practice guidelines of the International Conference on Harmonization and in keeping with local legal and regulatory requirements. Written informed consent was obtained prior to the patient entering the trial.

Consent for publication Not applicable. 


\section{Competing interests}

C.M.v.T. participated in Novartis and Bayer advisory boards.

C.R. participated in Amgen, Novartis, Pfizer, Roche, Genentech, Celgene, and SHIRE advisory boards.

J.B. received speech honoraria and travel support for scientific meetings from MSD Sharp \& Dohme.

O.W. participated in AstraZeneca and Novartis advisory boards.

T.S. participated in Merck and EUSA Pharma advisory boards.

The other authors declare that they have no competing interests.

\section{Author details}

'KiTZ Clinical Trial Unit, Hopp Children's Cancer Center Heidelberg (KiTZ), German Cancer Research Center (DKFZ) and Heidelberg University Hospital, Im Neuenheimer Feld 430, 69120 Heidelberg, Germany. ${ }^{2}$ Department of Pediatric Oncology, Hematology and Immunology, Heidelberg University Hospital, Heidelberg, Germany. ${ }^{3}$ Clinical Cooperation Unit Pediatric Oncology, German Cancer Research Center (DKFZ) and German Cancer Consortium (DKTK), Heidelberg, Germany. ${ }^{4}$ Division of Biostatistics, German Cancer Research Center (DKFZ) and German Consortium for Translational Cancer Research (DKTK), Heidelberg, Germany. ${ }^{5}$ Division of Neuroradiology, Heidelberg University Hospital, Heidelberg, Germany. ${ }^{6}$ Division of Pediatric Radiology, Heidelberg University Hospital, Heidelberg, Germany. 'Faculty of Biosciences, Heidelberg University, Heidelberg, Germany. ${ }^{8}$ DKTK Immune Monitoring Unit, German Cancer Research Center (DKFZ) and National Center for Tumor Diseases (NCT), Heidelberg, Germany. ${ }^{9}$ Swabian Children's Cancer Center, University Children's Hospital Augsburg, Augsburg, Germany. ${ }^{10}$ Children's Hospital, Bremen, Germany. ${ }^{11}$ Department of Pediatric Hematology and Oncology, University Children's Hospital Muenster, Muenster, Germany. ${ }^{12}$ Department of Pediatric Oncology and Hematology, Essen University Hospital, Essen, Germany. ${ }^{13}$ Division of Pediatric Oncology and Hematology, Freiburg University Hospital, Freiburg, Germany.

${ }^{14}$ Department of Pediatric Hematology and Oncology, University Medical Center Eppendorf, Hamburg, Germany. ${ }^{15}$ Department of Pediatrics, Jena University Hospital, Jena, Germany. ${ }^{16}$ Department of Pediatric Oncology and Hematology, Cologne University Hospital, Cologne, Germany. ${ }^{17}$ Department of Pediatric Oncology and Hematology, Hannover University Hospital, Hanover, Germany. ${ }^{18}$ Clinical Cooperation Unit Neuropathology, German Cancer Research Center (DKFZ) and German Consortium for Translational Cancer Research (DKTK), Heidelberg, Germany. ${ }^{19}$ Department of Neuropathology, Institute of Pathology, Heidelberg University Hospital, Heidelberg, Germany. ${ }^{20}$ Pharmacy Department, Heidelberg University Hospital, Heidelberg, Germany. ${ }^{21}$ NCT Trial Center, National Center for Tumor Diseases, German Cancer Research Center (DKFZ), Heidelberg, Germany. ${ }^{22}$ Department of Clinical Pharmacology and Pharmacoepidemiology, Heidelberg University Hospital, Heidelberg, Germany. ${ }^{23}$ Division of Pediatric Neurooncology, German Cancer Research Center (DKFZ) and German Cancer Consortium (DKTK), Heidelberg, Germany.

Received: 3 August 2019 Accepted: 3 November 2019 Published online: 10 December 2019

\section{References}

1. Bautista F, Di Giannatale A, Dias-Gastellier N, Fahd M, Valteau-Couanet D, Couanet D, Grill J, Brugieres L, Dufour C, Gaspar N, et al. Patients in pediatric phase I and early phase II clinical oncology trials at Gustave Roussy: a 13year center experience. J Pediatr Hematol Oncol. 2015;37(2):e102-10.

2. Gatta G, Botta L, Rossi S, Aareleid T, Bielska-Lasota M, Clavel J, Dimitrova N, Jakab Z, Kaatsch P, Lacour B, et al. Childhood cancer survival in Europe 1999-2007: results of EUROCARE-5--a population-based study. Lancet Oncol. 2014;15(1):35-47.

3. Vassal G, Rousseau R, Blanc P, Moreno L, Bode G, Schwoch S, Schrappe M, Skolnik J, Bergman L, Bradley-Garelik MB, et al. Creating a unique, multistakeholder Paediatric Oncology Platform to improve drug development for children and adolescents with cancer. Eur J Cancer. 2015;51(2):218-24.

4. Moreno L, Pearson ADJ, Paoletti X, Jimenez I, Geoerger B, Kearns PR, Zwaan CM, Doz F, Baruchel A, Vormoor J, et al. Early phase clinical trials of anticancer agents in children and adolescents - an ITCC perspective. Nat Rev Clin Oncol. 2017;14(8):497-507.

5. Eckschlager T, PIch J, Stiborova M, Hrabeta J: Histone deacetylase inhibitors as anticancer drugs. Int J Mol Sci 2017, 18(7).
6. Mann BS, Johnson JR, He K, Sridhara R, Abraham S, Booth BP, Verbois L, Morse DE, Jee JM, Pope $S$, et al. Vorinostat for treatment of cutaneous manifestations of advanced primary cutaneous T-cell lymphoma. Clin Cancer Res. 2007;13(8):2318-22.

7. Marks PA. Discovery and development of SAHA as an anticancer agent. Oncogene. 2007;26(9):1351-6.

8. Burke MJ, Lamba JK, Pounds S, Cao X, Ghodke-Puranik Y, Lindgren BR, Weigel BJ, Verneris MR, Miller JS. A therapeutic trial of decitabine and vorinostat in combination with chemotherapy for relapsed/refractory acute lymphoblastic leukemia. Am J Hematol. 2014;89(9):889-95.

9. DuBois SG, Groshen S, Park JR, Haas-Kogan DA, Yang X, Geier E, Chen E, Giacomini K, Weiss B, Cohn SL, et al. Phase I study of vorinostat as a radiation sensitizer with 1311-metaiodobenzylguanidine (131I-MIBG) for patients with relapsed or refractory neuroblastoma. Clin Cancer Res. 2015; 21(12):2715-21.

10. Fouladi M, Park JR, Stewart CF, Gilbertson RJ, Schaiquevich P, Sun J, Reid JM, Ames MM, Speights $R$, Ingle AM, et al. Pediatric phase I trial and pharmacokinetic study of vorinostat: a Children's Oncology Group phase I consortium report. J Clin Oncol. 2010;28(22):3623-9.

11. Hummel TR, Wagner $L$, Ahern C, Fouladi M, Reid JM, McGovern RM, Ames MM, Gilbertson RJ, Horton T, Ingle AM, et al. A pediatric phase 1 trial of vorinostat and temozolomide in relapsed or refractory primary brain or spinal cord tumors: a Children's Oncology Group phase 1 consortium study. Pediatr Blood Cancer. 2013;60(9):1452-7.

12. Muscal JA, Thompson PA, Horton TM, Ingle AM, Ahern CH, McGovern RM, Reid JM, Ames MM, Espinoza-Delgado I, Weigel BJ, et al. A phase I trial of vorinostat and bortezomib in children with refractory or recurrent solid tumors: a Children's Oncology Group phase I consortium study (ADVL0916). Pediatr Blood Cancer. 2013;60(3):390-5.

13. Iwamoto M, Friedman EJ, Sandhu P, Agrawal NG, Rubin EH, Wagner JA. Clinical pharmacology profile of vorinostat, a histone deacetylase inhibitor. Cancer Chemother Pharmacol. 2013;72(3):493-508.

14. Pinto N, DuBois SG, Marachelian A, Diede SJ, Taraseviciute A, Glade Bender JL, Tsao-Wei D, Groshen SG, Reid JM, Haas-Kogan DA, et al. Phase I study of vorinostat in combination with isotretinoin in patients with refractory/ recurrent neuroblastoma: a new approaches to Neuroblastoma Therapy (NANT) trial. Pediatr Blood Cancer. 2018;65(7):e27023.

15. Scheer C, Kratz C, Witt O, Creutzig U, Reinhardt D, Klusmann JH. Hematologic response to vorinostat treatment in relapsed myeloid leukemia of down syndrome. Pediatr Blood Cancer. 2016;63(9):1677-9.

16. Keshelava N, Houghton PJ, Morton CL, Lock RB, Carol H, Keir ST, Maris JM, Reynolds CP, Gorlick R, Kolb EA, et al. Initial testing (stage 1) of vorinostat (SAHA) by the pediatric preclinical testing program. Pediatr Blood Cancer. 2009;53(3):505-8.

17. Rettig I, Koeneke E, Trippel F, Mueller WC, Burhenne J, Kopp-Schneider A, Fabian J, Schober A, Fernekorn U, von Deimling A, et al. Selective inhibition of HDAC8 decreases neuroblastoma growth in vitro and in vivo and enhances retinoic acid-mediated differentiation. Cell Death Dis. 2015;6:e1657.

18. Ecker J, Oehme I, Mazitschek R, Korshunov A, Kool M, Hielscher T, Kiss J, Selt F, Konrad C, Lodrini M, et al. Targeting class I histone deacetylase 2 in MYC amplified group 3 medulloblastoma. Acta Neuropathol Commun. 2015;3:22.

19. Kelly WK, O'Connor OA, Krug LM, Chiao JH, Heaney M, Curley T, MacGregore-Cortelli B, Tong W, Secrist JP, Schwartz L, et al. Phase I study of an oral histone deacetylase inhibitor, suberoylanilide hydroxamic acid, in patients with advanced cancer. J Clin Oncol. 2005;23(17):3923-31.

20. Kelly WK, Richon VM, O'Connor O, Curley T, MacGregor-Curtelli B, Tong W, Klang M, Schwartz L, Richardson S, Rosa E, et al. Phase I clinical trial of histone deacetylase inhibitor: suberoylanilide hydroxamic acid administered intravenously. Clin Cancer Res. 2003;9(10 Pt 1):3578-88.

21. Hull EE, Montgomery MR, Leyva KJ. HDAC Inhibitors as epigenetic regulators of the immune system: impacts on cancer therapy and inflammatory diseases. Biomed Res Int. 2016;2016:8797206.

22. Ogawa Y, Ogura M, Tobinai K, Ando K, Suzuki T, Watanabe T, Ohmachi K, Uchida T, Hanson ME, Tanaka Y, et al. A phase I study of vorinostat combined with bortezomib in Japanese patients with relapsed or refractory multiple myeloma. Int J Hematol. 2016;103(1):25-33.

23. Ramalingam SS, Kummar S, Sarantopoulos J, Shibata S, LoRusso P, Yerk M, Holleran J, Lin Y, Beumer JH, Harvey RD, et al. Phase I study of vorinostat in patients with advanced solid tumors and hepatic dysfunction: a National Cancer Institute Organ Dysfunction Working Group study. J Clin Oncol. 2010; 28(29):4507-12. 
24. Rubin EH, Agrawal NG, Friedman EJ, Scott P, Mazina KE, Sun L, Du L, Ricke $J$, Frankel SR, Gottesdiener KM, et al. A study to determine the effects of food and multiple dosing on the pharmacokinetics of vorinostat given orally to patients with advanced cancer. Clin Cancer Res. 2006;12(23): 7039-45.

25. Fakih MG, Fetterly G, Egorin MJ, Muindi JR, Espinoza-Delgado I, Zwiebel JA, Litwin A, Holleran JL, Wang K, Diasio RB. A phase I, pharmacokinetic, and pharmacodynamic study of two schedules of vorinostat in combination with 5-fluorouracil and leucovorin in patients with refractory solid tumors. Clin Cancer Res. 2010;16(14):3786-94.

26. Williams MJ, Singleton WG, Lowis SP, Malik K, Kurian KM. Therapeutic targeting of histone modifications in adult and pediatric high-grade glioma. Front Oncol. 2017:7:45

27. Hahnen E, Eyupoglu IY, Brichta L, Haastert K, Trankle C, Siebzehnrubl FA, Riessland M, Holker I, Claus P, Romstock J, et al. In vitro and ex vivo evaluation of second-generation histone deacetylase inhibitors for the treatment of spinal muscular atrophy. J Neurochem. 2006:98(1):193-202.

28. Hockly E, Richon VM, Woodman B, Smith DL, Zhou X, Rosa E, Sathasivam K, Ghazi-Noori S, Mahal A, Lowden PA, et al. Suberoylanilide hydroxamic acid, a histone deacetylase inhibitor, ameliorates motor deficits in a mouse model of Huntington's disease. Proc Natl Acad Sci U S A. 2003;100(4):2041-6.

29. Spiller SE, Ditzler SH, Pullar BJ, Olson JM. Response of preclinical medulloblastoma models to combination therapy with 13-cis retinoic acid and suberoylanilide hydroxamic acid (SAHA). J Neurooncol. 2008;87(2):133-41.

30. Wang L. Leite de Oliveira R, Huijberts S, Bosdriesz E, Pencheva N, Brunen D, Bosma A, Song JY, Zevenhoven J, Los-de Vries GT et al: An acquired vulnerability of drug-resistant melanoma with therapeutic potential. Cell. 2018:173(6):1413-25 e1414

31. Khan O, Fotheringham S, Wood V, Stimson L, Zhang C, Pezzella F, Duvic M, Kerr DJ, La Thangue NB. HR23B is a biomarker for tumor sensitivity to HDAC inhibitor-based therapy. Proc Natl Acad Sci U S A. 2010;107(14):6532-7.

32. Yeo W, Chung HC, Chan SL, Wang LZ, Lim R, Picus J, Boyer M, Mo FK, Koh J, Rha SY, et al. Epigenetic therapy using belinostat for patients with unresectable hepatocellular carcinoma: a multicenter phase I/II study with biomarker and pharmacokinetic analysis of tumors from patients in the Mayo Phase II Consortium and the Cancer Therapeutics Research Group. J Clin Oncol. 2012;30(27):3361-7.

33. Pei Y, Liu KW, Wang J, Garancher A, Tao R, Esparza LA, Maier DL, Udaka YT, Murad N, Morrissy S, et al. HDAC and PI3K antagonists cooperate to inhibit growth of MYC-driven medulloblastoma. Cancer Cell. 2016;29(3):311-23.

34. Kroesen M, Gielen P, Brok IC, Armandari I, Hoogerbrugge PM, Adema GJ. HDAC inhibitors and immunotherapy; a double edged sword? Oncotarget. 2014:5(16):6558-72.

35. Kim K, Skora AD, Li Z, Liu Q, Tam AJ, Blosser RL, Diaz LA Jr, Papadopoulos N Kinzler KW, Vogelstein B, et al. Eradication of metastatic mouse cancers resistant to immune checkpoint blockade by suppression of myeloidderived cells. Proc Natl Acad Sci U S A. 2014;111(32):11774-9.

36. Agarwala SS, Moschos SJ, Johnson ML, Opyrchal M, Gabrilovich D, Danaher P. Efficacy and safety of entinostat (ENT) and pembrolizumab (PEMBRO) in patients with melanoma progressing on or after a PD-1/L1 blocking antibody. Journal of Clinical Oncology. 2018:36(15).

37. Gandhi L, Janne PA, Opyrchal M, Ramalingam SS, Rybkin II, Hafez N. Efficacy and safety of entinostat (ENT) and pembrolizumab (PEMBRO) in patients with non-small cell lung cancer (NSCLC) previously treated with anti-PD-(L) 1 therapy. Journal of Clinical Oncology. 2018:36(15).

38. Saltos AN, Tanvetyanon T, Williams CC, Haura EB, Creelan BC, Antonia SJ. Phase $\mathrm{I} / \mathrm{lb}$ study of pembrolizumab and vorinostat in patients with metastatic NSCLC (mNSCLC). Journal of Clinical Oncology. 2018:36(15).

39. Pili R, Liu G, Chintala S, Verheul H, Rehman S, Attwood K, Lodge MA, Wahl R, Martin Jl, Miles KM, et al. Combination of the histone deacetylase inhibitor vorinostat with bevacizumab in patients with clear-cell renal cell carcinoma: a multicentre, single-arm phase I/II clinical trial. British Journal of Cancer. 2017;116(7):874-83

40. Oki Y, Buglio D, Fanale M, Fayad L, Copeland A, Romaguera J, Kwak LW, Pro B, de Castro FS, Neelapu S, et al. Phase I study of panobinostat plus everolimus in patients with relapsed or refractory lymphoma. Clin Cancer Res. 2013;19(24):6882-90.

41. Oki Y, Buglio D, Zhang J, Ying Y, Zhou S, Sureda A, Ben-Yehuda D, Zinzani $\mathrm{PL}$, Prince HM, Harrison SJ, et al. Immune regulatory effects of panobinostat in patients with Hodgkin lymphoma through modulation of serum cytokine levels and T-cell PD1 expression. Blood Cancer J. 2014;4:e236.
42. Eisenhauer EA, Therasse P, Bogaerts J, Schwartz LH, Sargent D, Ford R, Dancey J, Arbuck S, Gwyther S, Mooney M, et al. New response evaluation criteria in solid tumours: revised RECIST guideline (version 1.1). Eur J Cancer. 2009:45(2):228-47.

43. Padhani AR, Ollivier L. The RECIST (Response Evaluation Criteria in Solid Tumors) criteria: implications for diagnostic radiologists. Br J Radiol. 2001; 74(887):983-6.

44. Therasse P, Arbuck SG, Eisenhauer EA, Wanders J, Kaplan RS, Rubinstein L, Verweij J, Van Glabbeke M, van Oosterom AT, Christian MC, et al. New guidelines to evaluate the response to treatment in solid tumors. European Organization for Research and Treatment of Cancer, National Cancer Institute of the United States, National Cancer Institute of Canada. J Natl Cancer Inst. 2000;92(3):205-16.

45. Brodeur GM, Pritchard J, Berthold F, Carlsen NL, Castel V, Castelberry RP, De Bernardi B, Evans AE, Favrot M, Hedborg F, et al. Revisions of the international criteria for neuroblastoma diagnosis, staging, and response to treatment. J Clin Oncol. 1993;11(8):1466-77.

46. Liu L, Detering JC, Milde T, Haefeli WE, Witt O, Burhenne J. Quantification of vorinostat and its main metabolites in plasma and intracellular vorinostat in PBMCs by liquid chromatography coupled to tandem mass spectrometry and its relation to histone deacetylase activity in human blood. J Chromatogr B Analyt Technol Biomed Life Sci. 2014;964:212-21.

47. Buhl JL, Selt F, Hielscher T, Guiho R, Ecker J, Sahm F, Ridinger J, Riehl D, Usta $D$, Ismer B, et al. The senescence-associated secretory phenotype mediates oncogene-induced senescence in pediatric pilocytic astrocytoma. Clin Cancer Res. 2018.

48. Capper D, Jones DTW, Sill M, Hovestadt V, Schrimpf D, Sturm D, Koelsche C, Sahm F, Chavez L, Reuss DE, et al. DNA methylation-based classification of central nervous system tumours. Nature. 2018;555(7697):469-74.

49. Sahm F, Schrimpf D, Jones DT, Meyer J, Kratz A, Reuss D, Capper D, Koelsche C, Korshunov A, Wiestler B, et al. Next-generation sequencing in routine brain tumor diagnostics enables an integrated diagnosis and identifies actionable targets. Acta Neuropathol. 2016;131(6):903-10.

50. Clopper C, Pearson ES. The use of confidence or fiducial limits illustrated in the case of the binomial. Biometrika. 1934;26:404-13.

51. Altman DG, Lausen B, Sauerbrei W, Schumacher M. Dangers of using "optimal" cutpoints in the evaluation of prognostic factors. J Natl Cancer Inst. 1994;86(11):829-35.

52. Helsel DR. Nondetects and data analysis: statistics for censored environmental data: John Wiley and Sons. New York: USA; 2005

\section{Publisher's Note}

Springer Nature remains neutral with regard to jurisdictional claims in published maps and institutional affiliations.
Ready to submit your research? Choose BMC and benefit from:

- fast, convenient online submission

- thorough peer review by experienced researchers in your field

- rapid publication on acceptance

- support for research data, including large and complex data types

- gold Open Access which fosters wider collaboration and increased citations

- maximum visibility for your research: over $100 \mathrm{M}$ website views per year

At $\mathrm{BMC}$, research is always in progress.

Learn more biomedcentral.com/submissions 